ORIGINAL ARTICLE

\title{
Acute Lower Gastrointestinal Bleed: Review of Clinical Course and Outcome in Hospitalized Patients
}

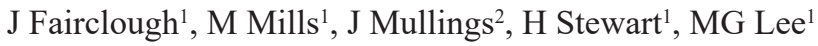

\begin{abstract}
Objective: This study reviewed the clinical features, aetiology and outcomes of patients with acute lower gastrointestinal bleed (ALGIB) admitted to the University Hospital of the West Indies, Jamaica, between January 2007 and December 2012.

Methods: Consecutive patients admitted with ALGIB were reviewed. Data collected comprised age, gender, prior episodes of ALGIB, co-morbid illness, vital signs, blood transfusion requirements, timing of colonoscopy and/or findings at surgery and outcomes.

Results: There were 189 patients reviewed with a mean age of 67 years. There was a predominance of females (55\% vs 45\%) with $80 \%$ of patients having at least one co-morbid illness. The use of aspirin and non-steroidal anti-inflammatory drugs (NSAIDs) was present in 24\% and $16 \%$ of patients, respectively. A previous diagnosis of diverticular disease was found in $31 \%$. Colonoscopy was performed in $72 \%$ of patients with a median time of four days to the procedure. Overall, $19 \%$ of patients required emergency surgery with no deaths. The leading causes of ALGIB were diverticular disease $56 \%$, colorectal cancer and haemorrhoidal disease $11 \%$ each and colonic polyps $8.5 \%$. Recurrent bleeding occurred in $3.7 \%$ and blood transfusion was given in 43\%. The average hospitalization stay was seven days, eight days for patients 65 years or older. Overall mortality was $2.6 \%$.

Conclusion: Acute lower gastrointestinal bleed occurred most frequently in the elderly population with the majority afflicted with co-morbid illnesses. Diverticular disease was the most common cause. Overall mortality (2.6\%) was low and emergency surgery is associated with low mortality. Older patients had a longer hospital stay.
\end{abstract}

Keywords: Colonoscopy, diverticula, gastrointestinal bleed

\section{Hemorragia Gastrointestinal Aguda Baja: Revisión del Curso Clínico y los Resultados en Pacientes Hospitalizados}

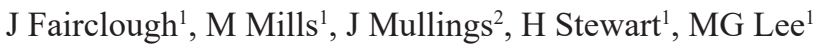

\begin{abstract}
RESUMEN
Objetivo: Este estudio examinó las características clínicas, la etiología y los resultados de pacientes con hemorragia gastrointestinal aguda baja (HGIAB) ingresados en el Hospital de la Universidad de West Indies, Jamaica, entre enero de 2007 y diciembre de 2012.
\end{abstract}

From: ${ }^{1}$ Department of Medicine and ${ }^{2}$ Faculty of Medical Sciences, The University of the West Indies, Kingston 7, Jamaica.
Correspondence: Professor MG Lee, Department of Medicine, The University of the West Indies, Kingston 7, Jamaica; Email: michael. lee@uwimona.edu.jm. 
Métodos: Se revisaron los pacientes consecutivos ingresados con HGIAB. Los datos recogidos incluyeron edad, sexo, episodios previos de HGIAB, enfermedades comórbidas, signos vitales, requerimientos de transfusiones sanguíneas, tiempo de colonoscopia y/o hallazgos en cirugía y resultados.

Resultados: Se realizó la revisión de 189 pacientes revisados con una edad promedio de 67 años. Hubo un predominio de mujeres (55\% vs $45 \%$ ) con un $80 \%$ de pacientes con al menos una enfermedad comórbida. El uso de aspirina y medicamentos antiinflamatorios no esteroideos (AINES) estuvo presente en 24\% y 16\%, respectivamente. Un diagnóstico anterior de la enfermedad de divertículos fue encontrada en 31\%. La colonoscopia se realizó en $72 \%$ de los pacientes con un tiempo promedio de cuatro días para el procedimiento. En general, el $19 \%$ de los pacientes requirieron cirugía de emergencia sin muertes. Las principales causas de HGIAB fueron la enfermedad diverticular con un 56\%, el cáncer colorrectal y la enfermedad de hemorroides con un $11 \%$ cada una, y los pólipos colónicos con $8.5 \%$. El sangramiento recurrente ocurrió en $3.7 \%$ y la transfusión de sangre fue requerida en $43 \%$. La estancia promedio de hospitalización fue de siete días; ocho días para los pacientes de 65 años o más. La mortalidad total fue de $2.6 \%$.

Conclusión: La hemorragia gastrointestinal aguda baja ocurrió más frecuentemente en la población de mayor edad, la mayor parte afligida con enfermedades comórbidas. La enfermedad diverticular fue la causa más común. La mortalidad total (2.6\%) fue baja y la cirugía de emergencia se asocia con una baja mortalidad. Los pacientes mayores tuvieron una estadia hospitalaria más prolongada.

Palabras clave: Hemorragia, colonoscopia, divertículos, gastrointestinal

West Indian Med J 2017; 66 (6): 680

\section{INTRODUCTION}

Acute lower gastrointestinal bleeding (ALGIB) is a common gastrointestinal indication for hospitalization and has a wide clinical spectrum from trivial bleeding to massive haemorrhage with shock. Bleeding occurs primarily in elderly patients and can result in substantial morbidity, mortality and resource utilization $(1,2)$. The rates of ALGIB are dependent on the population studied but is also impacted by the case definition as well as the tools used to make the diagnosis. The annual incidence of hospitalization from ALGIB is estimated to be 20-30 per 100000 persons in the United States of America [USA] $(2,3)$. A Europe-wide study showed that from 1995-2007, the incidence of lower gastrointestinal bleed (LGIB) increased by $60 \%$ and a study from The Netherlands revealed an overall incidence of 8.9 per 100 000 per year $(4,5)$.

The rates of ALGIB increases significantly with age, with the highest rates seen in those over 65 years old $(3,6,7)$. Concurrent with the older age distribution is a significant burden of co-morbid illness. The majority of patients with ALGIB have at least one co-existent medical condition (8). Other well established risk factors include, use of aspirin and non-steroidal anti-inflammatory drugs (NSAIDs), radiation therapy for prostate or cervical cancer, inflammatory bowel disease and coagulopathy $(9,10)$.

Over the last two decades, clinical and laboratory parameters have been identified as correlates of disease severity and these may impact prognosis. Clinical variables in the first four hours of presentation, and independent correlates of severe bleeding were, heart rate greater than 100 beats/minutes, systolic blood pressure less than $115 \mathrm{mmHg}$, syncope, non- tender abdominal examination, aspirin use and two or more co-morbid medical conditions (3). In another study, clinical predictors in the first hour included haematocrit less than 35\% and more than two units of blood transfusion during hospitalization (6). Most patients admitted with ALGIB have favourable outcomes. The mortality in most reviews is $5 \%$ or less, but can reach as high as $23 \%$ if the bleeding occurred after hospitalization $(3,11)$. Because most episodes of ALGIB will stop spontaneously, the early identification of high-risk patients would allow the more selective delivery of urgent therapeutic interventions to patients most likely to benefit (12). 
There are no local or regional data available regarding the frequency and outcomes of ALGIB. This study reviews the frequency, aetiology and outcomes of ALGIB at the University Hospital of the West Indies (UHWI). The results may assist in formulation of a protocol for management of ALGIB so as to achieve the best possible outcomes.

\section{SUBJECT AND METHODS}

Patients admitted to the UHWI over the six-year period between January 2007 and December 2012 with ALGIB were eligible for inclusion in the study. All patient records over the study period which were coded with a diagnosis of ALGIB including both the medical and surgical discharge registries were reviewed.

Data collected were gender, age, co-morbid illnesses, aspirin and NSAID use, prior ALGIB, vital signs at presentation, acute management, requirement for blood transfusion, duration of hospitalization, colonoscopy timing and findings and need for surgical intervention. Acute lower gastrointestinal bleeding was defined as hematochezia (bright red or maroon coloured stool) of recent onset, within three days, of emergency admission or occurring during hospitalization for another reason with a clear nasogastric lavage.

Exclusion criteria were documented haematemesis or coffee grounds and bleeding attributed to a cause identified proximal to the ligament of Treitz.

Ethical approval was granted for the study by the Ethics Committee of the University Hospital of the West Indies/ The University of the West Indies, Faculty of Medical Sciences, Mona, Jamaica.

The data collected were entered into SPSS version-19, analysis was done using descriptive and inferential statistics. Descriptive statistics was used to calculate and present summary data on the rate and frequency of the occurrence of ALGIB. The common aetiologies seen were presented as frequency tables and cross-tabulations. The determination of the relationship between the clinical variables such as age and haemodynamic status and in-hospital outcomes were achieved using inferential statistical tests such as Chi-square tests for non-parametric data and $t$-tests for parametric data. Logistic regression analyses were conducted to determine the predictors of specific in-hospital outcomes.

\section{RESULTS}

A total of 189 patients were confirmed to have ALGIB and were included in the study. There were more females, $55 \%$, than males, $45 \%$. The mean age was 67 years (range 27 to 96 years), 63 years for males and 70 years for females.

Eighty per cent of patients (151) had at least one comorbid illness: $30 \%$ had one co-morbidity, $24 \%$, two co-morbidities, $29 \%$ had three co-morbidities and $7 \%$ four co-morbidities. The use of aspirin and NSAIDs was seen in $24 \%$ and $16 \%$, respectively. Two patients were over-anticoagulated on coumadin therapy.

A previous diagnosis of ALGIB was noted in 38\% of patients (72), the majority of whom were females $(62.5 \%)$. A previous diagnosis of diverticular disease was found in $31 \%$ of patients and of these, $68 \%$ had at least one episode of ALGIB in the past. On presentation, the average systolic blood pressure was $127 \mathrm{mmHg}$ but $29 \%$ of patients had systolic blood pressure of 115 $\mathrm{mmHg}$ or lower. Six patients presented in circulatory shock and $8.5 \%$ had syncope. The mean haemoglobin at admission was $9.9 \mathrm{mg} / \mathrm{dL}$.

Colonoscopy was performed in $72 \%$ of patients (137) with an average time to colonoscopy of four days (range from 1-14 days). Colonoscopy was performed within 72 hours in $39 \%$ and $37 \%$ within four to six days. The reasons identified for late colonoscopies ( $>72$ hours) were, incomplete bowel preparation or poor patient tolerance of larger volumes of bowel purge. In-patient colonoscopy was not performed in $28 \%$ of patients (52). Emergency surgery was performed in $46 \%$ of these patients. The majority of patients (94\%) were seen and assessed in the emergency room by the surgical team but only $30 \%$ were admitted to the surgical wards. Overall 36 patients (19\%) required emergency surgery with no recorded deaths.

Diverticular disease was the most common identified cause for ALGIB and accounted for $56 \%$ in all patients. Other causes were colorectal cancer and haemorrhoidal disease $-11 \%$ each, colonic polyps $-8.5 \%$, ischaemic colitis $-5 \%$, ulcerative colitis $-3 \%$, radiation colitis $2 \%$ and others $-3 \%$.

Recurrent bleeding in hospital (defined as bleeding occurring after stable vital signs and serial haemoglobin for $\geq 24$ hours) was seen in only $3.7 \%$ of patients. Blood transfusion was required in $43 \%$ of the patient population (66\% requiring at least two units of blood) the mean number of packed red cells transfused was 1.8 units. The mean duration of hospitalization was seven days (six days for patients less than 65 years and eight days for patients 65 years or over) and the overall mortality was $2.6 \%$. 


\section{DISCUSSION}

Acute lower gastrointestinal bleed occurs most commonly in older patients and this was is seen in the present study as the mean age was 67 years. A similar pattern was noted in other studies, as in a large population based study in the United States of America, where the mean age was 68 years $(3,13)$. In another study, in Canada, the mean age was 70 years in patients admitted with ALGIB (14). In the present study, there were more females than males (55\% vs $45 \%)$ which is similar to a recent study of 140 patients with diverticular bleeding where there was a female preponderance (15). However, this is in contrast to other series which demonstrated a male preponderance $(3,14)$.

Concurrent with the older age distribution is a significant burden of co-morbid illnesses in patients admitted with ALGIB. Several reports consistently reveal that at least $70 \%$ of patients with ALGIB have one or more coexistent medical conditions (16). In one study with 252 patients with ALGIB, 78\% had at least one co-morbid medical condition (2). In this study, $80 \%$ of patients had at least one co-morbid illness. Non-steroidal antiinflammatory drugs and ASA are well established risk factors for ALGIB. A pervious study showed that $30 \%$ of patients with ALGIB were on NSAIDs and the risk for bleeding among those taking NSAIDs was 2.6 times those not taking them $(9,17)$. Also, the risk of bleeding from diverticular disease was increased by 3.4 times if with NSAID use (3). In this study, NSAIDs and ASA use was seen in $16 \%$ and $24 \%$ of the population, respectively.

A previous diagnosis of diverticular disease was present in $31 \%$ of patients in the present study and of these, $68 \%$ had at least one episode of ALGIB in the past. The finding that diverticulosis was the most common cause in $56 \%$ of ALGIB was slightly higher than that seen in most other series. Diverticular disease is common in the population of Western countries and increases to a prevalence of up to $60 \%$ in those aged over 80 years old. Prevalence is equal between men and women and acute diverticular bleeding affects $3 \%$ to $15 \%$ of individuals with diverticular disease (15).

In one study reporting on 219 patients with ALGIB, diverticulosis was identified as the cause in $42 \%$ (3). Other studies reported diverticular disease as the cause in $35 \%$ of patients $(18,19)$.

Colonoscopy is best performed in patients whose condition has been clinically stabilized and who are able to tolerate the bowel purge. There is increasing support for the role of early colonoscopy done 8-24 hours after admission which is thought to offer diagnostic and therapeutic opportunities and importantly may reduce the length of hospital stay in select populations $(2,16$, 20). The reduction in hospital stay seems to be primarily related to improve diagnostic yield rather than therapeutic interventions (2). However, the performance of colonoscopy on in-hospital patients with ALGIB can be fraught with frustration. Patients tend to have poor preparation and mobility status and their colonoscopies tend to be difficult to complete. Urgent colonoscopy is technically challenging, and is logistically complicated and resource intensive and it may not be appropriate or feasible for some patients $(2,21)$. In this study, $72 \%$ of patients had colonoscopy done with a mean time of four days after admission; of this total, $39 \%$ had the test done within three days. However, it should be noted that $46 \%$ of patients who did not have colonoscopy required emergency surgical intervention. The reasons identified for late colonoscopies ( $>72$ hours) were, incomplete bowel preparation or poor patient tolerance of larger volumes of bowel purge.

In a small study of 43 patients, urgent surgery was done in $16 \%$ of patients with ALGIB (22). The present study with a significantly larger sample size, $19 \%$ of patients required surgical intervention and there were no surgery deaths. It is reported that surgical intervention for lower gastrointestinal bleeding is necessary in $18-25 \%$ of patients (7). The mortality rate reported, range from $0-25 \%$ for ALGIB and is greater for patients who undergo emergency surgery (11). Additionally, patients who begin to bleed while hospitalized for a separate disease process have a higher-risk of death than those admitted with ALGIB [23\% vs 2.4\%] (3). The mortality rate in this study was $2.6 \%$ which is similar to previously reported studies of $2-4 \%(7,13,19)$. There was no difference in mortality whether patients had surgery or not or whether they were managed primarily by the surgical or medical team.

In the present study, only $3.7 \%$ of patients had documented recurrent bleeding in hospital, these figures were low compared to most other series which reported $7 \%-19 \%(2,23)$. The mean number of units of blood transfused was 1.8 units in this study which is similar to other reports $(2,23)$.

Predictors of poor outcome in ALGIB are not well defined (12). Establishing prognosis is an important first stage in aiding the patient with ALGIB as it may well affect the management strategies (24). The literature suggests many well established risk factors for poor outcome in ALGIB including, age, co-morbidity, initial haematocrit and the number of units of blood transfusion, 
are all independent risk factors for morbidity and mortality $(6,25)$. In the present study, there was no impact of the admitting haemoglobin, presenting vital signs and the presence of syncope on outcomes (need for transfusion, length of hospital stay, or mortality). Older patients ( $>65$ years) were found to have greater numbers of co-morbid illnesses and were admitted for longer durations. Overall, $31 \%$ of patients recorded systolic blood pressures of $115 \mathrm{mmHg}$ or less, six of these patients had circulatory shock which responded to fluid resuscitation, $43 \%$ required packed red cell transfusion (66\% requiring at least two units).

There were limitations to the present study. A clinical retrospective study may be associated with limitations with data collection as the data extracted may be limited and incomplete. Also, the management by different medical teams may affect the results obtained. Angiodysplasia was not a common cause reported in this series, which may in part be due to the fact that angiographic studies were not frequently performed. However, the results of this study will assist in formulation of a protocol for management of ALGIB in Jamaica to achieve best management and outcomes.

\section{ACKNOWLEDGEMENT}

The authors express sincere gratitude to the medical record staff who assisted with retrieving the files.

\section{AUTHORS' NOTE}

The authors have no conflict of interest in this work.

\section{REFERENCES}

1. Comay D, Marshall JK. Resource utilization for acute lower gastrointestinal hemorrhage: the Ontario GI bleed study. Can J Gastroenterol 2002; 16: $677-82$

2. Strate LL, Orav EJ, SyngalS. Early predictors of severity in acute lower intestinal tract bleeding. Arch Intern Med 2003; 163: 838-43.

3. Longstreth GF. Epidemiology and outcome of patients hospitalized with acute lower gastrointestinal hemorrhage: a population-based study. Am J Gastroenterol 1997; 92: 419-24.

4. Barnert J, Messmann H. Diagnosis and management of lower gastrointestinal bleeding. Nat Rev Gastroenterol. Hepatol 2009; 6: 637-46.

5. Oakland K, Mortensen N, Murphy M, Jairath V. UK-wide comparative audit of acute lower gastrointestinal bleeding and the use of blood transfusions in hospital treatment, to improve outcomes including a lower death rate for patients. Bowel Disease Research Foundation. October 2013

6. Velayos FS, Williamson A, Sousa KH, Lung E, Bostrom A, Weber EJ et al. Early predictors of severe lower gastrointestinal bleeding and adverse outcomes: a prospective study. Clin Gastroenterol Hepatol 2004; 2: 485-90.

7. Farrell JJ, Friedman LS. Management of lower gastrointestinal bleeding. Aliment Pharmacol Ther 2005; 21: 1281-98.

8. Strate LL, Syngal S. Timing of colonoscopy: impact on length of hospital stay in patients with acute lower intestinal bleeding. Am J Gastroenterol 2003; 98: 317-22.

9. Foutch PG. Diverticular bleeding: are non steroidal anti-inflammatory drugs risk factors for hemorrhage and can colonoscopy predict outcome for patients? Am Coll Gastroenterol 1995; 90: 1779-84.

10. Wilcox CM, Alexander LN, Cotsonis GA, Clark WS. Non-steroidal anti-inflammatory drugs are associated with both upper and lower gastrointestinal bleeding. Dig Dis Sci 1997; 42: 990-97.

11. Leitman IM, Paull DE, Shires GT. Evaluation and management of massive lower gastrointestinal hemorrhage. Ann Surg 1989; 209: 175-80.

12. Green BT, Rockey DC. Lower gastrointestinal bleeding-management. Gasteroenterol Clin N Amer 2005; 34: 665-78.

13. Brackman MR, Gushchin VV, Smith L, Demory M, Kirkpatrick JR, Stahl T. Acute lower gastroenteric bleeding. Retrospective analysis. An analysis of the triage, management and outcomes of patients with acute lower gastrointestinal bleeding. Amer Surgeon 2003; 69:145-49.

14. Al Qahtani AR, Satin R, Stern J, Gordon PH. Investigative modalities for massive lower gastrointestinal bleeding. World J Surg 2002; 26: $620-25$.

15. Jansen A, Harenberg S, Grenda U, Elsing C. Risk factors for colonic diverticular bleeding: A Westernized community based hospital study. World J Gastroenterol 2009; 28; 15: 457-61.

16. Jensen DM, Machicado GA, Jutabha R, Kovacs TOG. Urgent colonoscopy for the diagnosis and treatment of severe diverticular hemorrhage. N Engl J Med 2000; 342: 78-82.

17. Wilcox CM, Clark WS. Association of non-steroidal anti-inflammatory drugs with outcome in upper and lower gastrointestinal bleeding. Digest Dis Sci 1997; 42: 985-89.

18. Schmulewitz N, Fisher DA, Rockey DC. Early colonoscopy for acute lower GI bleeding predicts shorter hospital stay: a retrospective study of experience in a single center. Gastrointest Endosc 2003; 58: 841-46.

19. Gayer C, Chino A, Lucas C, Tokioka S, Yamasaki T, Edelman DA et al. Acute lower gastrointestinal bleeding in 1112 patients admitted to an urban emergency medical center. Surgery 2009; 146: 600-7.

20. Chaudhry V, Hyser MJ, Gracias VH, Gau FC. Colonoscopy: the initial test for acute lower gastrointestinal bleeding. Am Surg 1998; 64: 723-28.

21. Enns R, Krygier D. The inpatient colonoscopy: a difficult endeavor. Can J Gastroenterol 2008; 22: 900-2.

22. Rios A, Montoya MJ, Rodriguez JM, Serrano A, Molina J, Parrilla P. Acute Lower Gastrointestinal hemorrhages in geriatric patients. Dig Dis Sci 2005; 50: 898-904.

23. Das A, Ben-Menachem T, Cooper GS, Chak A, Sivak MV, Gonet JA et al. Prediction of outcome in acute lower-gastrointestinal haemorrhage based on an artificial neural network: internal and external validation of a predictive model. Lancet 2003; 362: 1261-66.

24. Inouye SK, Peduzzi PN, Robison JT, Hughes JS, Horwitz RI, Concato J. Importance of functional measures in predicting mortality among older hospitalized patients. JAMA 1998; 279: 1187-93.

25. Hussain H, Lapan S, Cappell MS. Clinical scoring systems for determining the prognosis of gastrointestinal bleeding. Gastroenterol Clin North Am 200; 29: 445-64. 